\title{
Trends in Second/Foreign Language Teaching and Learning: The Position Assigned to the Learning of Lexis over the Years
}

\author{
Debbita Tan \\ School of Languages, Literacies and Translation, Universiti Sains Malaysia, 11800 Penang, Malaysia \\ E-mail: debbita_tan@usm.my
}

Doi:10.7575/aiac.alls.v.7n.6p.84

URL: http://dx.doi.org/10.7575/aiac.alls.v.7n.6p.84
Received: 08/08/2016

Accepted: 15/10/2016

\begin{abstract}
There is no doubt that second/foreign language teaching and learning has evolved over the years, distinguishing varied trends in the course of its history. Interestingly, vocabulary has been the dominant focus in the last decades despite it being an undervalued and often overlooked component in the earlier stages. This reorientation is reflected not only in terms of classroom practices and education policies, but also in second/foreign language acquisition (SLA) research. The following seeks to provide an understanding of the position assigned to lexis within the scope of different methods implemented throughout the years, thus allowing us to: 1) trace the evolvement of the significance of vocabulary in SLA, and 2) appreciate the importance of lexical development in SLA. In congruity with these elements, current trends and practices related to second/foreign language vocabulary knowledge development are also discussed. This paper is of significance to scholars, researchers, language educators and curriculum designers.
\end{abstract}

Keywords: SLA, lexis, lexical development, vocabulary learning, historical trends, current approaches

\section{Introduction}

In recent decades, we have witnessed a general consensus among scholars, researchers and teachers that lexical development plays an essential role in mastering a second or foreign language. Apart from classroom practices and educational policies governing SLA, the crucial role that vocabulary plays in language competence has been increasingly acknowledged in language acquisition research, particularly so within the domain of second/foreign language acquisition. This, however, was not the case in earlier times when lexical development was largely considered secondary, even unnecessary, and explicit attention was rarely accorded to the learning of new words.

Today, the scenario is very different. In fact, language learners themselves consider vocabulary knowledge to be of primary importance and believe that their difficulties in both receptive and productive language use stem from inadequate vocabulary knowledge, a situation which begs us to consider, evaluate and apply currently available strategies to encourage vocabulary development. The present paper traces the evolvement of the significance of vocabulary in second/foreign language acquisition over the years, and offers a look at several approaches, related to second/foreign language vocabulary knowledge development, that can be included as part of our classroom practices for the benefit of our learners.

\section{The Significance of Vocabulary in Second/Foreign Language Acquisition over the Past Decades}

\subsection{The Grammar-Translation Method}

It was not until the eighteenth century that modern languages started to be studied, and they were initially taught in largely the same way as classical languages like Latin and Greek. The primary objectives of the Grammar-Translation Method (GTM) were to prepare students to read and write classical texts, and the materials used often consisted of classical literature (Zimmerman, 1997) which, according to Espinosa (2003), exposed students to obsolete lexis.

Originally reformist in nature, the approach was an attempt at making language learning easier through the use of sample sentences instead of utilising entire texts or passages (Howatt, 1984). However, it developed into a very pedantic system. It included heavy emphasis on accuracy and detailed grammar rules (many of which were quite abstruse), paradigms for memorisation, and bilingual vocabulary lists to learn - most of which exposed students to obsolete vocabulary as well as archaic structures and prepared them primarily for the regular task of translating long passages of the classics (Espinosa, 2003; Schmitt, 2000; Zimmerman, 1997).

It is argued that the GTM did, in actual fact, accord importance to vocabulary acquisition. Coady (1993), for instance, pointed out that the method appeared to prioritise vocabulary, in line with Kelly (1969, cited in Zimmerman, 1997) who noted that direct vocabulary instruction was a part of the GTM and that bilingual dictionaries became common reference tools during that period. However, it was also observed that lexical items were selected according to their capacity to illustrate grammatical rules (Rivers, 1981) and, as Kelly (1969, cited in Zimmerman, 1997) admitted, direct vocabulary instruction was executed only when a word addressed a grammatical rule. 
A new pedagogical direction became necessary when the GTM, concerned with both obscure and obsolete elements, grew increasingly impractical. One of the major problems of the approach was that it concentrated on one's ability to analyse language and not the ability to use it (Schmitt, 2000). Espinosa (2003) concurred by stressing that the approach did little to promote the practical use of the target language because it specifically trained students to read and write classical materials as well as pass standardised tests. In other words, the students were not fully expected to use the target language in real situations.

Despite receiving criticism for many years, the GTM was still in practice till the $1920 \mathrm{~s}$ (Espinosa, ibid.). In the $1880 \mathrm{~s}$, however, its critics garnered sufficient consensus and intellectual leadership from linguists like Henry Sweet to establish the Reform Movement; Sweet was assertive in his opinion that the failure of previous attempts to discredit the GTM was mainly due to insufficient knowledge of the science of language (Zimmerman, 1997). 2.2 The Reform Movement

The Reformers placed strong emphasis on three basic principles: a) the primacy of spoken language, b) the centrality of the connected text as the kernel of the teaching-learning process, and c) the absolute priority of an oral classroom methodology (Howatt \& Widdowson, 2004).

Zimmerman (1997) pointed out that, as opposed to the GTM, Sweet's lessons prioritised accurate pronunciation as well as meticulously controlled speech, and excluded the study of isolated sentences and lists of words out of context; grammar points and lexical items were separated or isolated for instructional purposes only after a thorough study of the complete text is done.

Furthermore, the lexical items learnt were practical and associated with the real world, a timely intervention in addressing the neglect of realistic language use resulting from the GTM which was largely preoccupied with both the obscure and the obsolete. As Zimmerman (1997) remarked: "Perhaps the Reformers' most significant departure from the past in the area of vocabulary instruction was that words came to be associated with reality rather than with other words and syntactic patterns. To this end, vocabulary was selected according to its simplicity and usefulness." (p. 8)

According to Howatt and Widdowson (2004), Sweet combined his methodologies into a graded curriculum which comprised five stages, a design considered to be representative of the era (Howatt, 1984). The initial stage was the Mechanical Stage, a level devoted to the study of phonetics and transcription as well as the acquisition of good pronunciation, followed by the Grammatical Stage at which students studied grammar and basic vocabulary. It was at the Idiomatic Stage that lexis was pursued at greater depth and where vocabulary development was accorded exclusive attention. Stages four and five, Literary and Archaic respectively, consisted of university-level work focusing on literature and philology (Howatt \& Widdowson, 2004; Zimmerman, 1997).

\subsection{The Direct Method}

The Direct Method, although deemed baseless in terms of linguistic theory by intellectual leaders such as Henry Sweet, gained foothold on account of the debates which supervened during the Reform Movement (Richards \& Rodgers, 1986). Developed by Sauveur in America and made popular by Berlitz, the approach upheld interaction as the heart of natural language acquisition and stressed on relating meaning directly with the target language without the inclusion of translation (Zimmerman, 1997).

The Reform Movement was responsible for the interest in developing standards of language teaching parallel to the naturalistic principles of language learning. This ultimately led to what has been termed as 'natural methods', for which the Direct Method is the best known.

It was contended by Sauveur that a foreign language could be taught without having to rely on the use of a learner's first language, on condition that meaning was conveyed directly through action and demonstration (Richards \& Rodgers, 1986). Comparably, German scholar F. Franke (1884, cited in Richards \& Rodgers, ibid.) presented theoretical justifications for a monolingual approach to language teaching by observing the psychological principles of direct association between forms and meanings in the target language. He suggested that a language was best taught through its active use in the classroom and that known words be used to aid in the acquisition of new ones, via the employment of tools and techniques such as visual materials and mimes. With regards to grammar, Franke was in favour of an inductive approach rather than analytical procedures or deductive means (i.e., the intensive study of grammar rules).

The Direct Method enjoyed success in commercial language schools, such as those of the Berlitz chain established by Maximilian Berlitz who referred to the approach as the Berlitz Method (Richards \& Rodgers, ibid.). However, despite its popularity, the Direct Method was perceived to have several drawbacks (Schmitt, 2000) and even considered counterproductive, with Henry Sweet claiming that although the concept offered innovative teaching techniques, it lacked a comprehensive methodological foundation (Richards \& Rodgers, 1986).

Other critics, on the other hand, pointed out factors that made it infeasible for the method to be implemented in public schools, stating that it: a) overemphasised and distorted the similarities between naturalistic first language learning and classroom foreign language learning, and b) failed to take into consideration the practical realities of a classroom; strict adherence to the principles of the Direct Method required teachers to go to great lengths to avoid using the native tongue and resort to complex demonstrations when often a simple explanation in the student's native language would not only have sufficed, but would also have proven to be a more efficacious course towards achieving comprehension (Richards \& Rodgers, ibid.; Zimmerman, 1997). 
Harvard psychologist Roger Brown (1973) reported similar dissatisfactions with the Direct Method, and described his frustrations while observing a language instructor perform "verbal gymnastics" (p. 5) in an attempt to convey the meanings of certain words when in actual fact a brief translation would have been a more efficient technique to use.

\subsection{The Reading Method and Situational Language Teaching}

A study on the state of foreign language teaching began in 1923 and was published in 1929 as the Coleman Report, recommending that students be taught how to read in a foreign language, which was considered the most useful skill one could acquire from schooling; simultaneously, Michael West in Britain was emphasising the importance of advancing vocabulary learning in order to facilitate reading skills (Schmitt, 2000).

These developments eventually coalesced into an approach called the Reading Method, acknowledged as the pioneering method in terms of prioritising lexis in second/foreign language learning. According to Richards and Rodgers (1986), it was with the Reading Method that for the first time vocabulary was considered one of the most essential aspects of foreign language learning, in tandem with West (1930, cited in Espinosa, 2003) who commented that "the primary thing in learning a language is the acquisition of a vocabulary, and practice in using it" (p. 514).

West (ibid.) was of the opinion that foreign language learners lacked lexical prowess and failed to possess a basic thousand-word vocabulary even after three years of study because they: a) expended time on activities that were not helping them speak the language, b) were learning words that were not useful to them, and c) were not fully mastering the words they were learning. He recommended the use of word-frequency lists and in 1953 published $A$ General Service List of English Words, in line with the recommendations of the Carnegie Report which strongly suggested the development of a vocabulary list that would be instrumental in the production of simple reading materials (Schmitt, 2000). Meara (1980) highlighted that despite the list being old, it is considered the most widely used of high-frequency word lists and publishers still quote West's 1953 list even though there are more updated ones in existence.

At the same time, H.E. Palmer and A.S. Hornby, British linguists and leaders of the Situational Language Teaching movement, were aiming to establish a more scientific foundation for the oral methods made popular by direct methodologists (Zimmerman, 1997). Palmer and Hornby laid strong emphasis on the selection, gradation and presentation of language structures. The Oral Approach, the general tenets of which were established by Palmer, Hornby and other British linguists, stressed on introducing and practising new language points situationally. This tenet became a key feature of the approach; it was then that the term 'situational' turned increasingly popular in referring to the Oral Approach, and the term 'Situational Language Teaching' eventually came into common usage (Richards \& Rodgers, 1986).

As mentioned earlier, vocabulary was considered a central element in second/foreign language learning during this period. For the purpose of selecting the vocabulary content of language courses, priority was placed on developing a basis that was scientifically inclined as well as driven by rationale (Zimmerman, 1997). It is observed that the combined work of Palmer and West led to the development of principles on vocabulary control, and their attempts at introducing a scientific basis for vocabulary selection were in fact the very first efforts at establishing standards of syllabus design in language teaching.

\subsection{The Audio-Lingual Method}

The Audio-Lingual Method was founded by Charles Fries as a new approach to pedagogical grammar rather than merely as a new method for foreign language teaching and learning. The approach stood for the following principles and practices (Schmitt, 2000; Zimmerman, 1997; Coady, 1993; Larsen-Freeman, 1986):

a) Most problems experienced by foreign language learners concern the conflict of varying structural systems

b) Language learning is a process of habit formation

c) Systematic attention is concentrated on pronunciation and intensive oral drilling of basic sentence patterns

d) Grammatical points are taught through examples and drills instead of analysis and memorisation of rules

e) New vocabulary is rationed and only introduced when necessary to keep the drills viable

f) Lexical items are selected based on their simplicity and familiarity because the emphasis is on teaching structural patterns

With regards to the importance of vocabulary, the assumption was that the structural frames could be "fleshed out with words at a later stage when students were more certain of their lexical needs in particular situations" (Rivers, 1983, p. 118). Fries (1945, cited in Zimmerman, 1997) harnessed his opinion on vocabulary learning by quoting Edward Sapir: "The linguistic student should never make the mistake of identifying a language with its dictionary." (p. 38)

Fries was of the opinion that language learners in general oversimplified the role of isolated words and that this oversimplification contributed to three erroneous assumptions: a) words possess exact equivalents in different languages, b) a word is a single-meaning unit, and c) each word has a "real" meaning and all other meanings are figurative. 
Rivers $(1981,1968)$ put forth that excessive vocabulary learning allows for the impression that the most important thing in language learning lies in the accumulation of new words as equivalents for concepts which the learners can already express in their native tongues. She recommended that learners be exposed to morphological variations and syntactic structures instead, using familiar words rather than new ones in order to discourage distraction from focusing on the target structures. It is to be noted that Rivers altered this position in her later work.

In essence, it was widely suggested during this period that too much vocabulary learning in the early stages of a language acquisition process gives rise to a false sense of security among learners. Twaddell (1980) highlighted that due to language learners' tendency to overvalue word knowledge, teachers and theoreticians reacted by downgrading the role of vocabulary and consequently overemphasizing the role of grammar, resulting in adult learners having "an infantile vocabulary and an adult mentality" (p. 442).

\subsection{Communicative Language Teaching}

A major shift in linguistic theory occurred in the late 1950s when American linguist Avram Noam Chomsky introduced the assumption that language learning is facilitated by an innate knowledge of certain principles that guide individuals in developing the grammar of their language. In other words, language acquisition is a human instinct driven by grammatical machineries already internalised in the brain. Chomsky's publication of Syntactic Structures in 1957 advanced the idea that language is represented in the speaker's mental grammar by an abstract set of rules that is most clearly reflected in his or her unconscious intuitions about the language.

Chomsky's work was revolutionary and challenged the behaviourist view of language learning as a set of habits as well as the views of constructivists like Jean Piaget who considered all cognitive acquisitions to be the outcome of the gradual process of construction. Piaget's central idea was that knowledge develops neither solely from the experience of objects nor from an innate programming in the subject, but from successive constructions.

In his fifth book on the evolution of language, Lieberman (2000) echoed the message of his earlier books and asserted that language is a learnt skill rather than an innate instinct or predisposition. He postulated that language is not in instinct, based on genetically transmitted knowledge coded in a discrete cortical language organ, but is instead a learnt skill and that the human capacity for language is based on a 'functional language system' distributed across different parts of the brain, allowing for parallel processing to occur in neural structures associated with higher cognition, perception, and even motor control.

Also, reacting to Chomsky's proposition, Hymes (1972) proposed the concept of 'communicative competence' which gave greater emphasis to the sociolinguistic and pragmatic factors governing effective language use. Hymes did not completely reject Chomsky's views and defined communicative competence not only as an inherent grammatical competence, but also as the ability to use grammatical competence in different communicative situations.

In essence, it was discerned during this period that language learning entails more than mere habit formation, and that communicative competence embodies linguistic competence in the form of linguistic creativity. This led to a change in language instruction methods whereby communicative proficiency was given priority over structural control. According to Richards and Rodgers (1986), communicative language teaching strove to "make communicative competence the goal of language teaching and develop procedures for the teaching of the four language skills that acknowledge the interdependence of language and communication" (p. 66).

Vocabulary was not the primary focus of explicit attention in communicative language research or methodology (Zimmerman, 1997). Second language acquisition was considered analogous to first language acquisition and it was hence assumed that a learner's L2 vocabulary would gradually develop in the course of his or her L2 acquisition, similar to vocabulary development in L1 (Coady, 1993). This was also noted by Zimmerman (1997) who pointed out that the underlying assumption of communicative approaches was that since vocabulary development occurs naturally in L1 through contextualised, naturally sequenced language, it will therefore also occur through natural, communicative exposure in L2.

Nevertheless, a common aim of communicative methods was the promotion of fluency over accuracy and with regards to this, Rivers (1983), in considering how to help learners communicate meaning successfully, encouraged language instructors to pay more attention to vocabulary. Similarly, Widdowson (1978) observed that it is easier to comprehend ungrammatical utterances with accurate vocabulary than those with accurate grammar but inaccurate vocabulary. Wilkins (1974), meanwhile, commented on the fundamental importance of words and suggested substantial exposure to the target language as the only way to master its lexical system.

\section{Second/Foreign Language Vocabulary Knowledge Development: Current Approaches}

\subsection{Incidental Vocabulary Learning}

According to Rieder $(2003,2002)$, incidental vocabulary learning occurs through the process of inferring word meanings when the learner encounters unknown or unfamiliar words when engaging in tasks such as reading. Extensive reading (ER) - essentially independent reading, broadly and in quantity over a continual period of time - is one of the primary means of learning vocabulary incidentally.

The method has proven to be successful in not only improving vocabulary and grammatical knowledge, but has also managed to develop positive attitudes towards second/foreign language reading among learners of all levels. Day and Bamford (1998), among the leading proponents of ER, outlined the following ten criteria found in successful ER programmes: 
a) Students read as much as possible

b) A variety of materials on a wide range of topics is available

c) Reading materials are well within the linguistic competence of the students

d) Students select what they want to read

e) Students read for pleasure, information and general understanding

f) Reading is individual and silent

g) The reading rate or speed is usually faster

h) Reading is its own reward (post-reading activities are discouraged)

i) The teacher is a role model of a reader, an active member of the classroom reading community

j) Students are oriented to the programme's goals, given guidance, and their progress tracked

Guided by these tenets, different ER approaches have been carried out as interventions and even without applying all ten tenets, these approaches have produced encouraging findings.

For instance, Tan (2016) carried out ER-based interventions using graded readers on university-level remedial English language learners in Malaysia and found that despite excluding criteria 4, 8 and 9 for one group and criteria 4 and 9 for another group, the participants still enjoyed the interventions and more importantly, demonstrated significant receptive and productive vocabulary knowledge development post-treatment. See Tan, Pandian and Jaganathan (2016) for a list of suggested protocols to facilitate the implementation of a graded/guided reading programme in ESL/EFL settings. Teachers may elect to complement their reading programme with post-reading activities (e.g., vocabulary worksheets) if they prefer applying an approach that covers both incidental and intentional vocabulary learning.

Apart from graded readers, teachers may also use much shorter texts such as articles or short stories in their reading programmes. Rashidi and Adivi (2010) investigated the correlation between vocabulary gains and the reading of specific short stories, and found significant incidental vocabulary gains in comparison to the outcome of explicit instruction. Their research involved 40 Iranian EFL learners divided into two groups. The participants of the experimental group were assigned five short stories for the purpose of comprehension while those in the control group were explicitly taught the target words.

More recently, Webb and Chang (2015) investigated the extent of vocabulary learning through reading while listening to graded readers, and reported high vocabulary gains. 82 secondary school EFL students in Taiwan participated in the study and 61 of them were assigned to the experimental group; they simultaneously read and listened to one graded reader per week and experienced post-reading activities such as discussions about the storylines and characters. A total of ten Level One graded readers from the Oxford Bookworm series were used, along with their corresponding professionally recorded audio versions.

\subsection{Intentional Vocabulary Learning}

Other than reliance of incidental means alone, language learners in general actually stand to reap a lot of benefits from intentional vocabulary learning which, according to Ellis $(2005,1999)$, involves the purposeful learning of lexical information through activities such as direct vocabulary study.

Isolating words from their contexts and studying them ensures not only that the correct meaning is learnt, but also heightens the potential for the words to be reinforced and as a result, to be better retained. Rosszell (2007) pointed out that decontextualised word study in fact "acts as a buttress against the potentially inefficient or faulty learning outcomes that can result from an over-reliance on a strategy of inferring word meanings from context" (p. 59).

Commonly, there are two approaches to intentional vocabulary learning: the teacher/classroom-centred approach and the independent approach. What is more important, however, is the consensus that both approaches can be effective and the realisation that they can only be effective if we go beyond mere memorisation or rote-learning. In order to promote better knowledge retention, it is vital that elaborate cognitive processing takes place during learning (Tan, Pandian, \& Jaganathan, 2015).

Webb (2005) reported results, on both receptive and productive measures, indicating the superiority of writing tasks for vocabulary knowledge retention (see also Liu, 2011). Roszzell (2007) also emphasised the importance of sentence production tasks, and in his research utilised vocabulary worksheets that require learners to generate original and meaningful sentences.

Based on these views, a vocabulary worksheet template is provided below for teachers' use with their students (Figure 1). The worksheet is designed to improve both receptive and productive vocabulary knowledge, and can be used together with a dictionary or with teacher guidance. A maximum of 20 words per week is recommended. 
Word: beautiful

Form: Adjective

1 This word is related to the following idea:

2 This word means:

3 Make an original and meaningful sentence using the word 'beautiful':

Figure 1. Vocabulary Worksheet Template

(Receptive and Productive Vocabulary Knowledge Development)

\section{Conclusion}

In sum, the position assigned to lexis over the years in second/foreign language acquisition has evolved and undergone a remarkable shift from, as put forth by Maiguashca (1993), poor relation to guest of honour. Tracing this evolvement allows us to appreciate the importance of lexical development in SLA and in turn, prompts us to identify the best ways to teach and learn vocabulary.

The question today is no longer 'Should we focus on vocabulary?' or 'What kind of vocabulary should we teach?', but rather 'How do we get students to learn vocabulary effectively?'. The central importance of vocabulary knowledge in language acquisition - first, second or foreign - is obvious, and having control over both the receptive and productive measures is indispensable. It is noteworthy that although many vocabulary teaching and learning strategies have been made available to us, it is pertinent for us to constantly gauge their suitability, adapt them to the immediate needs of our learners, evaluate their effectiveness and most importantly, improve upon them.

\section{References}

Brown, R. (1973). A first language: The early years. Cambridge, MA: Harvard University Press.

Chomsky, N. (1957). Syntactic structures. The Hague, Paris: Mouton.

Coady, J. (1993). Research on ESL/EFL vocabulary acquisition: Putting it in context. In T. Huckin, M. Haynes \& J. Coady (Eds.), Second language reading and vocabulary learning (pp. 3-23). Norwood, NJ: Ablex.

Day, R.R., \& Bamford, J. (1998). Extensive reading in the second language classroom. Cambridge, UK: Cambridge University Press.

Ellis, N.C. (2005). At the interface: Dynamic interactions of explicit and implicit language knowledge. Studies in Second Language Acquisition, 27, 305-352.

Ellis, R. (1999). Learning a second language through interaction. Amsterdam/Philadelphia: John Benjamins.

Espinosa, S.M. (2003). Vocabulary: Reviewing trends in EFL/ESL instruction and testing. Odisea, 4, 97-112.

Howatt, A.P.R. (1984). A history of English language teaching. Oxford, UK: Oxford University Press.

Howatt, A.P.R., \& Widdowson, H.G. (2004). A history of English language teaching (Second Edition). Oxford, UK: Oxford University Press.

Hymes, D.H. (1972). On communicative competence. In J.B. Pride \& J. Holmes (Eds.), Sociolinguistics: Selected readings (pp. 269-293). Harmondsworth, England: Penguin Books.

Larsen-Freeman, D. (1986). Techniques and principles in language teaching. Oxford, UK: Oxford University Press.

Lieberman, P. (2000). Human language and our reptilian brain: The subcortical bases of speech, syntax, and thought. Cambridge, MA: Harvard University Press.

Liu, Y. (2011). Vocabulary recognition and memorization: A comparison of two methods. Kristianstad University, Sweden. Retrieved from http://www.diva-portal.org/smash/get/diva2:429600/FULLTEXT01.pdf

Maiguashca, R.U. (1993). Teaching and learning vocabulary in a second language: Past, present, and future directions. The Canadian Modern Language Review, 50(1), 83-100.

Meara, P. (1980). Vocabulary acquisition: A neglected aspect of language learning. Language Teaching and Linguistics, 13(4), 221-246.

Rashidi, N., \& Adivi, A.G. (2010). Incidental vocabulary learning through comprehension-focused reading of short stories. Journal of English Language Teaching and Learning, 53(217), 111-129. 
Richards, J.C., \& Rodgers, T.S. (1986). Approaches and methods in language teaching. Cambridge, UK: Cambridge University Press.

Rieder, A. (2002). A cognitive view of incidental vocabulary acquisition: From text meaning to word meaning. VIEWS, $11(1 \& 2), 53-71$.

Rieder, A. (2003). Implicit and explicit learning in incidental vocabulary acquisition. VIEWS, 12(2), 24-39.

Rivers, W.M. (1968). Teaching foreign-language skills. Chicago, IL: University of Chicago Press.

Rivers, W.M. (1981). Teaching foreign-language skills (Second Edition). Chicago, IL: University of Chicago Press.

Rivers, W.M. (1983). Communicating naturally in a second language: Theory and practice in language teaching. New York, NY: Cambridge University Press.

Rosszell, H.R. (2007). Extensive reading and intensive vocabulary study in a Japanese university. (Unpublished doctoral thesis). Temple University, Japan.

Schmitt, N. (2000). Vocabulary in language teaching. Cambridge, UK: Cambridge University Press.

Tan, D.A.L. (2016). Investigating guided extensive reading and vocabulary knowledge performance among remedial ESL learners in a public university in Malaysia. (Unpublished doctoral thesis). Universiti Sains Malaysia, Malaysia.

Tan, D.A.L., Pandian, A., \& Jaganathan, P. (2015). Reading for lexical development: Depth of processing and the systematic selection of comprehensible input. International Journal of Educational Research, 3(7), 109-120.

Tan, D.A.L., Pandian, A., \& Jaganathan, P. (2016). Encouraging ESL/EFL reading among lower proficiency students at the tertiary level: The use of graded readers. The Reading Matrix: An International Online Journal, 16(2), 20-36.

Twaddell, F. (1980). Vocabulary expansion in the TESOL classroom. In K. Croft (Ed.), Readings on English as a second language (Second Edition) (pp. 439-457). Cambridge, MA: Winthrop.

Webb, S. (2005). Receptive and productive vocabulary learning: The effects of reading and writing on word knowledge. Studies in Second Language Acquisition, 27, 33-52.

Webb, S., \& Chang, A.C.S. (2015). Second language vocabulary learning through extensive reading with audio support: How do frequency and distribution of occurrence affect learning? Language Teaching Research, 19(6), 667-686.

Widdowson, H.G. (1978). Teaching language as communication. Oxford, UK: Oxford University Press.

Wilkins, D.A. (1974). Second-language learning and teaching. London, UK: Edward Arnold.

Zimmerman, C.B. (1997). Historical trends in second language vocabulary instruction. In J. Coady \& T. Huckin (Eds.), Second language vocabulary acquisition: A rationale for pedagogy (pp. 5-19). Cambridge, UK: Cambridge University Press. 